\title{
Suboptimal birth spacing practice and associated factors among women of reproductive age in West Badwacho district, Hadyia zone, South Ethiopia, 2020: Cross-sectional study design
}

\author{
Alemu Workineh Wassihun \\ Hawassa University College of Medicine and Health Sciences \\ Yilkal Simachew Hunegnaw ( $\nabla$ joemakalister123@gmail.com ) \\ Teshome Abuka Abebo \\ Hawassa University College of Medicine and Health Sciences \\ Alex Yeshaneh Bekele \\ Wolkite University
}

Hawassa University College of Medicine and Health Sciences https://orcid.org/0000-0003-1293-3986

Research

Keywords: Birth interval, suboptimal, birth spacing

Posted Date: May 7th, 2021

DOI: https://doi.org/10.21203/rs.3.rs-421636/v1

License: (c) (i) This work is licensed under a Creative Commons Attribution 4.0 International License.

Read Full License 


\section{Abstract}

Introduction: Birth spacing is the time gaps between two consecutive life births. One of the key strategies to reduce fertility and promote the health status of mothers and their children is optimal birth spacing. Recent evidences showed that the health of mothers and children with the birth interval of 3 to 5 years is safer than 2 years or less. However, women still have shorter birth intervals and studies addressing their associated factors were scarce.

Objectives: To assess prevalence of suboptimal birth spacing practice and its associated factors among women of reproductive age in West Badwacho district, Hadyia Zone, South Ethiopia, 2020.

Method and materials: Community based cross sectional study was conducted from February to March, 2020. Multi stage sampling technique was used to select samples of 626 women. Structured and pretested interview based questionnaire was used to collect the data. Data was checked for completeness and entered using EPI data version 3.1 and analyzed using SPSS version 25. Bivariable logistic regression was done and variables with a $p$-value of $<0.25$ in bi-variable logistic regression were recruited as candidate variable for the final multivariable logistic regression model and $P$ value less than 0.05 at $95 \%$ confidence level was taken as statistically significant.

Result: The prevalence of suboptimal birth interval in this study was $60.4 \%$. Independent predictors of suboptimal birth spacing were: age at first marriage less than 18 years (AOR: 2.18, 95\% Cl=1.34,3.53), HEWs education about birth sapcing (AOR: $1.89,95 \% \mathrm{Cl}=1.02,3.48$ ), non -formal maternal education (AOR: 2.25, 95\% Cl=1.31,3.87), non -formal husband education (AOR: $2.64,95 \% \mathrm{Cl}=1.74,4.01$ ), sex of index child being female (AOR:1.58, 95\% Cl=1.06, 2.38),, having poor knowledge on optimal birth interval (AOR: $2.96,95 \% \mathrm{Cl}=1.64,5.37$ ), duration of breast feeding for less than 24 months (AOR: $4.64,95 \% \mathrm{Cl}=2.32,9.29$ ), and modern contraceptive non users (AOR: 6.31, 95\% Cl=3.99,9.96),

Conclusion and recommendation: More than half of the study respondents were practicing suboptimal birth interval. Educational status, age at first marriage, HEWs education about birth sapacing, short duration of breastfeeding was some of the factors associated with the outcome variable. Thus, to optimize birth spacing, strategies of providing information using HEWs, education and communication targeting associated variables should be improved.

\section{Plain English Summary}

Birth spacing is the time gaps between two consecutive life births. One of the key strategies to reduce fertility and promote the health status of mothers and their children is optimal birth spacing. However, women still have shorter birth intervals and studies addressing their associated factors were scarce. Different studies have shown that suboptimal birth spacing practice was influenced by multiple factors such as maternal related factors, birth history factors like place of delivery, survival status of previous child and others. In Ethiopia, different programs and strategies are implemented to optimize the birth spacing practice including community based intervention which is education by health extension workers 
(HEWs) is one of the strategy. Despite this, different studies overlooked to see the effect of health extension program (HEP) on suboptimal birth spacing practice.

Out of 626 women $60.4 \%$ of women with child bearing are had practiced suboptimal birth spacing. In this study, factors associated with suboptimal birth spacing were age at first marriage less than 18 years, HEWs education about birth spacing, non -formal maternal and husband education, of index child being female, having poor knowledge on optimal birth interval, duration of breast feeding for less than 24 months and modern contraceptive non users.

Awareness of the modern contraceptives use, the importance of breastfeeding as a birth spacing mechanism and the impact of early marriage are recommended. In addition education about family planning and birth spacing should be encouraged by HEWs.

\section{Introduction}

Birth spacing is the gap between two successive live births. Based on live birth it is composed of three components namely, postpartum amenorrhea (PPA), waiting time to conception and gestation $(1,2)$. Optimal birth spacing refers to resting period between two consecutive live births that allows a woman to have adequate time to replenish nutritional stores to the next pregnancy and birth. Thus, USAID recommend that births should be spaced at three to five years apart to ensure maximum health benefits for mothers, newborns, and older children. When women space their births below three years birth interval it is named as suboptimal birth spacing $(1,3)$. However, too long birth intervals ( $>5$ years) are associated with increased risk of infant deaths and other adverse maternal outcomes like preeclampsia and eclampsia as the mother loses protective effect from the previous pregnancy (4).

Among the most recent DHS surveys in 46 countries around all regions of the world, the average percentage of births in the optimal birth interval is 31 percent. Thus more than two-thirds of non-first births occur in an interval less than 24 months .Overall, almost one in four births occurred after an interval of less than 24 months (5). In the developing region, $57 \%$ of the 1.6 billion women of reproductive age desire to space births for at least 2 years or to limit childbearing at all (6). Even though the desire is high, birth intervals below 24 months account $36 \%$ of births in many sub-Saharan countries in which Ethiopia had $20 \%$ of births occurring within 24 months of the previous birth (7). Recent studies in Jimma and Lemo district of Ethiopia revealed that $59.7 \%$ and $57.6 \%$ of women practice suboptimal birth spacing respectively $(8,9)$.

A short birth interval is known to have negative effects on maternal, perinatal and neonatal outcomes as well as on child health (4). According to one population based case control study inter pregnancy interval $<6$ months, as compared with a reference of 18 to 23 months were associated with increased odds of still birth (10). United States Agency for International Development also confirmed that in less developed countries if no births occur within thirty-six months of a preceding birth, infant mortality and under-five mortality rates would drop by $2 \%$ and $35 \%$ respectively (11). These can also be supported by study in 
Bangladesh which revealed as infants born with a short birth-to-birth interval of $<36$ months had higher odds of first-day neonatal mortality (12).

According to data from Ethiopian Demographic and Health Survey (EDHS) of 2016, short birth intervals substantially reduce children's chances of survival, especially if the interval is less than two years. In addition to health impact, closely spaced birth intervals increase population growth and affect economic development (3).Inter-Censual Population Survey 2012 estimated Ethiopia has 83.7 million total populations which made the second most populous country in Africa next to Nigeria (13). If fertility were to remain constant at current levels, a woman from Ethiopia would bear an average of 4.6 children in her lifetime which is still high (14).

Different studies have shown that suboptimal birth spacing practice was influenced by multiple factors such as maternal related factors, birth history factors like place of delivery, survival status of previous child and others. Socioeconomic and demographic factors are also important indirect determinants of suboptimal birth spacing practice $(8,15,16)$. In Ethiopia, different programs and strategies are implemented to optimize the birth spacing practice including community based intervention which is education by health extension workers (HEWs) is one of the strategy. Despite this, different studies overlooked to see the effect of health extension program (HEP) on suboptimal birth spacing practice.

Even though women in developing countries prefer optimum birth interval, they are still practicing short birth interval (1). In Ethiopia like many other Sub-Saharan African countries, fertility, maternal mortality, and child mortality are still high. Recent estimates of EDHS 2016 and mini EDHS 2019 showed that the country still experiences higher rates of maternal, neonatal, and infant mortality of 412/100,000, 30/1000, and 43 per 1000 live births, respectively $(14,18)$.

In addition, little is known about the current level of birth spacing and associated factors in Ethiopia and particularly in the study area. Factors affecting suboptimal birth spacing also vary within the context and areas of study $(8,9,16,19,20)$. Thus, understanding the level of birth interval and factors influencing birth spacing is critical for countries like Ethiopia with a population policy aiming at reducing fertility. This study therefore aims to fill this gap by assessing the current level of inter birth interval and its associated factors among reproductive age women in West Badwacho district, SNNPR, Ethiopia.

\section{Methods And Materials}

\section{Study setting and design}

Community based cross sectional study was conducted among child bearing age women's from February to March 2020 in West Badwacho district, Hadyia Zone, South Ethiopia. West Badwacho district is one of 11 districts found in Hadiya zone. It is located $283 \mathrm{~km}$ apart from Addis Ababa, which is the capital city of Ethiopia and about $127 \mathrm{~km}$ apart from Hawassa which is the capital city of SNNPR as well as $97 \mathrm{~km}$ apart from Hossana which is capital city of Hadiya zone. Based on West Badwacho district health department report there are 4 health centers and 22 health posts serving 2 urban and 20 rural kebeles 
with an estimated total population of 113,265 from which female were 57,131 in 2019 . From this Child bearing age mothers in the district are 26,391 and it has a total of 22,998 households (21). Majority of the residents of the district are Hadiya in ethnicity followed by Kambata. Agriculture served as economic base for majority of community members in the district.

\section{Population}

\section{Source population}

Source population were women of child-bearing age (15-49) living in district who have at least two consecutive births.

\section{Study population}

Study population were selected women of child-bearing age (15-49) living in district who have at least two consecutive births and the last delivery being within the past five years prior to data collection.

\section{Inclusion and Exclusion criteria}

Women in reproductive age group (15-49) having at least two children, woman who gave the last birth within the past five years and Women who are permanently resided in the area were included. Women having serious health problem in terms of their illness make them unable to give response to questions were excluded.

\section{Sample Size determination}

Sample size determination for specific objective one

Sample was determined using the formula for single population proportion by using suboptimal birth interval of $57.6 \%$ proportion from study conducted at Lemo district, Southern Ethiopia (9) and considering $95 \%$ level of confidence, $5 \%$ margin of error, 1.5 design effect and $10 \%$ nonresponse rate.

\section{EQUATION 1}

Where: $d=$ margin of error $(5 \%=0.05)$

$P=$ best estimate of population proportion $(57.6=0.576)$

$Q=1-P=0.424$

$Z=$ confidence level $(95 \%=1.96)$

$\mathrm{n}=$ sample size

Sample size will be: 
EQUATION 2

When $10 \%$ non-response rate is added it become 413 and after multiplying by 1.5 design effect the final sample size was 626 .

\section{Sample size determination for specific objective two}

For factors the sample size was calculated using Epi info version 7.2 STAC CALC double population proportion formulas. Previous similar literatures were referred and proportion of suboptimal birth practice among non -exposed groups of reviewed factors was taken .For each factors power of $80 \%$,confidence level of $95 \%$ and 1:1 Unexposed to exposed ratio was considered.

Table 1: Summary of sample size calculation for main exposure variables associated with suboptimal birth spacing practice using variables from different literatures

\begin{tabular}{|lllllll|}
\hline Factors & $\begin{array}{l}\text { Proportion among non- } \\
\text { exposed }\end{array}$ & Ratio & AOR & $\mathrm{Cl}$ & $\begin{array}{l}\text { Sample } \\
\text { size }\end{array}$ & Reference \\
\hline $\begin{array}{l}\text { Maternal age at } \\
\text { first marriage }\end{array}$ & 22.9 & $1: 1$ & 2.05 & $1.19,3.69$ & 322 & $(8)$ \\
$\begin{array}{l}\text { Contraceptive } \\
\text { use }\end{array}$ & 27.4 & $1: 1$ & 1.94 & $1.09,3.45$ & 348 & $(8)$ \\
$\begin{array}{l}\text { Age of the } \\
\text { mother }\end{array}$ & 27.8 & $1: 1$ & 1.94 & $1.01,3.69$ & 346 & $(11)$ \\
$\begin{array}{l}\text { at last } \\
\text { pregnancy }\end{array}$ & & & & & & \\
\hline $\begin{array}{l}\text { Sex of index } \\
\text { child }\end{array}$ & 29.6 & & & & & \\
\hline
\end{tabular}

From the factors the one which gives larger sample size in which 348 was taken. By comparing with sample size of specific objectives the larger sample which is 626 from specific objective one was taken as a final sample size.

\section{Sampling techniques and procedure}

Multi stage sampling technique was used to select study subjects. First, simple random sampling used to select six kebeles (the smallest administrative units in a given district in Ethiopia) from a total of 22 kebeles in the district. The selected six kebeles has 7363 households with maximum households from Danema 01 which is 1737 and the minimum households from J/Mazoria which is 857 . House to house visit (census) using family folder from health extension workers was conducted in all selected kebeles to identify women who fulfill the inclusion criteria. The households which have women who fulfill the 
inclusion criteria were coded in each selected kebeles for the purpose of preparing sampling frame. The calculated sample size was allocated proportionally. to the size of populations in each selected kebeles. Then, simple random sampling was used to select the study units from coded households.

\section{Study Variables}

Dependent variable: Suboptimal birth spacing

Independent variables: Socio-demographic variables (Age, marital status,educational status, religion, occupation, residence), birth history, contraceptive use, breast feeding practice, preference of birth interval ,awareness to optimal birth spacing practice, HEWs education about optimal birth spacing.

\section{Operational definitions}

Optimal birth interval: it denotes to $3-5$ years' birth interval (including 3 and 5 years) between the birth of the child under study and the immediately preceding live and surviving birth to the mother(1).

Short or suboptimal birth interval: it refers to less than 3 years' birth interval between the birth of the child under study and the immediately preceding live and surviving birth to the mother(3).

Long birth interval: it refers greater than 5 years' birth interval between the births of the child under study and the immediately preceding live and surviving birth to the mother (1).

Knowledge/awareness: women who respond more than $60 \%$ from knowledge questions for optimal birth spacing practice will be considered as aware of optimal birth spacing practice (11).

Index child: the first child of recent two births.

Breast feeding practice: it refers the duration of the breast feed in which the woman feeds her index child.

Decision making role: it refers the family member who decides for receiving maternal health services.

\section{Data collection tool}

The data was collected using pre-tested interview guided structured questionnaire. The questionnaire was prepared in English and was translated to local language Hadiyssa and checked for its consistency by translating it back to English by those who are well oriented with the stated languages (language Professionals or experts). The questionnaire contains: socio-demographic characteristic of the study respondents, Awareness of the study respondents on birth spacing, birth history of the study respondents, breastfeeding practice, use of modern contraceptives and household wealth index items. House hold wealth index is estimated by principal component analysis based on house hold variables which was taken and modified accordingly from EDHS 2016.The instrument was adapted from different literatures developed for similar purpose by different authors $(8,11,16,19)$.

\section{Data collection procedure}


To collect the data two diploma Nurses, three BSc Midwifes and one Public health officer who are fluent in speaking local language were recruited as data collectors, while one BSc midwife and one public health officer were recruited for supervising and coordinating. Following recruitment, information was provided about the data collection instruments in depth and the supervisors supervise the day to day data collection activity together with the principal investigator. The data was collected from respondents through face-to-face interview with selected participant at their home. In case of more than one reproductive age women who fulfill the inclusion criteria found in randomly selected households, the data collectors selected one woman by lottery method. Women who did not exist during the visit time in randomly selected households were revisited until three times and after that another random selection was conducted from the frame.

\section{Data quality assurance}

To keep the quality of data, the English version questionnaire was translated in to Hadiyyissa and then back to English to maintain its consistency for actual data collection purpose with great emphasis given to local vocabularies. Detail training for data collectors and supervisors was given on the objectives of the study and how to interview, how to fill the questionnaire and handle questions asked by respondents during interviewing by the principal investigator for two days. Furthermore, feedback and correction on daily basis for the data collectors before they deployed to the field was performed and completeness, accuracy, and clarity of the collected data was checked carefully by the principal investigator and supervisor. Before the actual data collection, pre-test was carried out on $5 \%$ of the sample size on the kebele outside actual data collection named Deda. Reliability of the data collection tool for knowledge items was checked by Cronbach's alpha $(r=0.92)$.

\section{Data processing and analysis}

After the collected data checked for consistency and completeness, and entered into Epi Data version 3.1 then, data was analyzed using SPSS version 25.0. Bi-variable logistic regression analysis was used to see significance of association between dependent and each independent variable. P-Value less than 0.05 was taken as statistically significant and Multi-variable logistic regression model was used to control for possible confounding variables, to examine association and to produce adjusted odds ratio along with their corresponding confidence limits $(95 \% \mathrm{Cl})$. The fitness of logistic regression models was assessed using the Hosmer-Lemeshow test at $p>0.05$. Multicollinearity test was carried out to see the correlation between each independent variable, using variance inflation factor (VIF) and tolerance test. A p-value of < 0.25 in bivariable logistic regression was used to recruit candidate variables for the final multivariable

logistic regression model. Finally, the findings were presented in the form of text, tables and graphs as appropriate.

\section{Result}

Socio-demographic characteristic of mothers of child bearing age in West Badwacho district 
A total of 626 mothers were participated in this study, and all (626) of them were interviewed for collecting the data giving the response rate of $100 \%$.

The median age of study respondents was 30 years with IQR of 30 years. Most, 585 (93.5\%) of the respondents were married while the rest 38 (6.5\%) were others include divorced and widowed. Median Age during their first marriage was 19 years with IQR of 19 years. Five hundred sixty eight $(90.7 \%)$ of respondents were protestant followers in religion, and five hundred thirty six (85.6\%) were Hadiyya by ethnic group. About three quarter $(75.1 \%)$ of respondents live in rural area. More than half $(51.9 \%)$ of the respondents were unable to read and write, while $14.2 \%$ attended secondary and above education. The occupation of majority of the respondents is housewife, followed by farmers for 357 (57\%) and 152 $(24.3 \%)$ respectively. About two hundred forty one (38.5\%) of the study respondents were found poor based on estimated wealth index (Table 2).

Table 2: Socio-demographic and economic characteristic of mothers of child bearing age in West Badwacho district ,Hadyia Zone ,South Ethiopia, 2020, (N=626) 


\begin{tabular}{|c|c|}
\hline Variables & Frequency (\%), $\mathrm{N}=626$ \\
\hline \multicolumn{2}{|c|}{ Age of mothers } \\
\hline $20-24$ & $112(17.9)$ \\
\hline $25-29$ & $181(28.9)$ \\
\hline $30-34$ & $140(22.4)$ \\
\hline $35-39$ & $142(22.7)$ \\
\hline$\geq 40$ & $51(8.1)$ \\
\hline \multicolumn{2}{|c|}{ Marital status of respondents } \\
\hline Married & $585(93.5)$ \\
\hline Divorced & $29(4.6)$ \\
\hline Widowed & $12(1.9)$ \\
\hline \multicolumn{2}{|c|}{ Residence of respondents } \\
\hline Urban & $156(24.9)$ \\
\hline Rural & $470(75.1)$ \\
\hline \multicolumn{2}{|c|}{ Religion of respondents } \\
\hline Protestant & $568(90.7)$ \\
\hline Orthodox & $49(7.9)$ \\
\hline Catholic & $9(1.4)$ \\
\hline \multicolumn{2}{|c|}{ Ethnicity of respondents } \\
\hline Hadiya & $536(85.6)$ \\
\hline Kambata & $42(6.7)$ \\
\hline Welayta & $26(4.2)$ \\
\hline Others ${ }^{a}$ & $22(3.5)$ \\
\hline \multicolumn{2}{|c|}{ Age at first marriage } \\
\hline$<18$ years & $250(39.9)$ \\
\hline$\geq 18$ years & $376(60.1)$ \\
\hline \multicolumn{2}{|c|}{ Duration of marriage } \\
\hline$<10$ years & $300(47.9)$ \\
\hline$\geq 10$ years & $326(52.1)$ \\
\hline
\end{tabular}




\begin{tabular}{|ll|}
\hline Educational status of mothers & \\
\hline Read and to read and write & $325(51.9)$ \\
\hline Primary education(1-8) & $131(20.9)$ \\
\hline Secondary education(9-12) & $49(7.8)$ \\
\hline College and above & $40(6.4)$ \\
\hline Occupational status of mothers & \\
\hline House wife & $357(57)$ \\
\hline Farmers & $152(24.3)$ \\
\hline Government employee & $30(4.8)$ \\
\hline Business women & $87(13.9)$ \\
\hline Wealth index of respondents & Wealth index of respondents \\
\hline Poor 241 (38.5) & $241(38.5)$ \\
\hline Medium 123 (19.6) & $123(19.6)$ \\
\hline Rich 244 (39.0) & $244(39.0)$ \\
\hline
\end{tabular}

a others: Amhara, Gurage

\section{Birth History and awareness about birth spacing among mothers of child bearing age in West Badwacho district}

Most, 553 (88.3\%) of respondents had informed about optimum birth spacing. Among those informed, there was variation in understanding regarding appropriate time length between two births. More than half, (55.1\%) replied 36-60 months as an appropriate time length between two consecutive births. Majority, 486 (77.6\%) of the study respondents agreed that an optimal birth interval has health advantages both for the mother and child whereas particularly 466 (74.4\%) were reported short birth interval has health disadvantages both for mother and the child. Regarding to the possessed number of children, more than one third of the respondents 245 (39.1\%) have three to four children and, however 47 $(7.5 \%)$ of mothers reported child death soon after birth. Majority of the index child were female which accounts for 341 (54.5\%), whereas 285 (45.5\%) were male. Concerning the preference of birth interval; more than half of respondents, 403 (64.4\%) prefer 3-5 years birth interval. Near to half the respondents 290( 46.4) have took education by health extension workers (HEWs) about optimal birth spacing (Table 3).

Table 3: Birth History and knowledge about birth spacing among mothers of child bearing age in West Badwacho district ,Hadyia Zone ,South Ethiopia, 2020 ,(N=626) 


\begin{tabular}{|c|c|}
\hline Variables & Frequency (\%), $\mathrm{N}=626$ \\
\hline \multicolumn{2}{|c|}{ Mothers heard b/n two consecutive births } \\
\hline Yes & $551(88)$ \\
\hline No & $75(12)$ \\
\hline \multicolumn{2}{|c|}{ Advantage for both mother and child } \\
\hline Yes & $486(77.6)$ \\
\hline No & $114(18.2)$ \\
\hline I don't know & $26(4.2)$ \\
\hline \multicolumn{2}{|c|}{ Disadvantage for both mother and child } \\
\hline Yes & $466(74.4)$ \\
\hline No & $134(21.4)$ \\
\hline I don't know & $26(4.2)$ \\
\hline \multicolumn{2}{|c|}{ Knowledge about optimal birth spacing } \\
\hline Poor & $111(11.7)$ \\
\hline Good & $515(82.3)$ \\
\hline \multicolumn{2}{|c|}{ Number of live birth } \\
\hline$\leq 2$ & $154(24.6)$ \\
\hline $3-4$ & $245(39.1)$ \\
\hline$\geq 5$ & $227(36.3)$ \\
\hline \multicolumn{2}{|c|}{ Death soon after birth } \\
\hline Yes 47 (7.5) & $47(7.5)$ \\
\hline No $579(92.5)$ & $579(92.5)$ \\
\hline \multicolumn{2}{|c|}{ Preference of birth interval } \\
\hline$<$ three years & $129(20.6)$ \\
\hline $3-5$ years & $403(64.4)$ \\
\hline$>5$ years & $94(15)$ \\
\hline \multicolumn{2}{|c|}{ Sex of index child } \\
\hline Male & $255(40.7)$ \\
\hline Female & $371(59.3)$ \\
\hline
\end{tabular}

Page 12/25 


\begin{tabular}{|ll|}
\hline ANC visit for index child & \\
\hline No & $388(93.9)$ \\
\hline Place of delivery for index child & $38(6.1)$ \\
\hline Institutional & $447(71.4)$ \\
\hline Home & $179(28.6)$ \\
\hline PNC visit for index child & \\
\hline Yes & $598(95.5)$ \\
\hline No & $28(4.5)$ \\
\hline HEWs ${ }^{\text {a Birth sapcing education }}$ \\
\hline Yes & $290(46.4)$ \\
\hline No & $336(53.6)$ \\
\hline
\end{tabular}

a HEW, Health Extension Workers

Distribution of birth intervals by duration in months among mothers of child bearing age in West Badwacho district

\section{Breastfeeding practice for index child among mothers of child bearing age in West Badwacho district}

All, six hundred twenty six (100\%) of mothers in child bearing age of West Badwacho district have breastfed their last child. Among those who breastfed their last child, almost all 565 (90.3\%) breastfed their last child for less than 24 months whereas 61 (9.7\%) breast feed 24 months and above. About 505 (80.7\%) of mothers have practiced exclusive breast feeding while the rest 119 (19\%) didn't practice exclusive breast feeding (Table 4).

Table 4: Breastfeeding practice among mothers of child bearing age in West Badwacho district, Hadyia Zone ,South Ethiopia, $2020,(\mathrm{~N}=626)$ 


\begin{tabular}{|ll|}
\hline Variables & Frequency (\%) ,N =626 \\
\hline Breast feed their last child & \\
\hline Yes & Yes $626(100)$ \\
\hline No & 0 \\
\hline Duration of breast feeding & $565(90.3)$ \\
\hline$<24$ months & $61(9.7)$ \\
\hline 24 months and above & \\
\hline Exclusive breast feeding & $505(80.9)$ \\
\hline Yes & $119(19.1)$ \\
\hline No & \\
\hline Reasons for not breast feeding & $252(40.3)$ \\
\hline Child old enough & $306(48.9)$ \\
\hline New pregnancy & $22(3.5)$ \\
\hline Health problems & $46(7.3)$ \\
\hline Others ${ }^{a}$ & \\
\hline
\end{tabular}

a Others include, lack of service, lack of information, no husband

\section{Contraceptive usage after index child among mothers of child bearing age in West Badwacho district}

About Six hundred eleven (97.6\%) of the study respondents had information about at least one modern Contraceptive used to space and limit birth. As figure 4 above has depicted contraceptives used to space and limit child birth, however a few of them used some of those contraceptives. This indicates that the respondents were high while their actual use of the methods was too low. The most frequently known contraceptive was pills 606 (96.8\%) followed by injectable 603 (96.3\%), Implants $416(66.5 \%)$ and IUCD 334 (53.4\%). Regarding usage implants was the most frequently used $160(25.6 \%)$ and IUCD was the least frequently used 20 (3.2\%).

\section{Predictors of suboptimal birth interval among mothers of child bearing age in West Badwacho district}

In Bi-variable logistic regression, age of the mother, residence, maternal educational, ,maternal occupation, husband education ,age at first marriage, duration of marriage, sex of the index child, number of live birth , knowledge of the interval $b / n$ to consecutive births, duration of breast feeding, and use of modern contraceptives for index child were the variables that showed statistically significant association with the outcome variable that is suboptimal birth interval. In order to control the effect of confounders, multiple logistic regressions enter condition method was performed and computed the adjusted odds 
ratio. Maternal education, husband education, age at first marriage, duration of marriage, knowledge of the interval between two consecutive births, sex of the index child, duration of breast feeding, and use of modern contraceptives were found to be the independent predictors of short birth interval.

The likelihood of practicing suboptimal birth interval was about 2 times more likely in mothers who were married at age less than 18 years as compared to mothers who were married at age 18 years and above (AOR ;2.18,95\% Cl $(1.34,3.53)$ ). The practice of suboptimal birth interval was about 2 times more on women who were not got education from HEWs as compared to the women who got education about birth spacing from HEWs (AOR; $1.89,95 \% \mathrm{Cl}(1.02,3.48)$ ). The odds of practicing short birth interval was about 2 times more likely in respondents who had no formal education as compared to those who had formal education (AOR: $2.25,95 \% \mathrm{Cl}(1.31,3.87)$ ). The odds of practicing short birth interval was about 2.6 times more likely in respondents whose husbands had no formal education as compared to those who had formal education (AOR: $2.65,95 \% \mathrm{Cl}(1.74,4.01)$ ) .

The probability of having female index child was about 1.5 times more likely to increase the chance of getting short birth as compared to those mothers who had male index child (AOR ;1.58, 95\% Cl (1.06, 2.38)). The practice of suboptimal birth interval on respondents who had poor knowledge about birth interval between two consecutive births was about 3 times as compared to mothers who had good knowledge (AOR;2.96 ,95 Cl (1.65,5.37)). The likelihood of practicing suboptimal birth interval was about 5 times more likely in mothers who were breastfeed less than 24 months as compared to mothers who were breast feed 24 months and above (AOR; $4.64,95 \% \mathrm{Cl}(2.32,9.29))$.Study respondent who had not used modern contraceptives were about 6 times more likely to practice suboptimal birth spacing as compared to those who had used modern contraceptives (AOR; 6.31, 95\% Cl $(3.99,9.96)$ ) (Table 5).

\section{Discussion}

This study tried to assess the practice and associated factors of suboptimal birth spacing among women of child bearing age in West Badwacho district, Hadiya Zone, Southern Ethiopia.

Majority of the respondents had short birth interval. Age at first marriage, duration of marriage ,maternal education, husband's education, knowledge of mothers on optimum birth spacing, sex of index child, duration of breast feeding, and contraceptive use were independent predictors of child spacing among women of reproductive age.

This study revealed that suboptimal birth spacing practice was found to be $60.4 \%, 95 \% \mathrm{Cl}(56.54$, 64.22). This finding is in line with study conducted in Sudan, Jimma Zone and Hadiya Zone which was $60.6 \%, 59.9 \%$ and $57.6 \%$ respectively $(8,9,22)$. However, it is higher than the studies done in lllubabor Zone (51.2\%), Debremarkos (40.9\%), and Tanzania $(48.4 \%)(19,23,24)$. The difference in prevalence across studies could be explained by socio demographic feature of the study participants, the time gaps between the study periods, accessibility of contraceptive methods and the difference in data collection methods. 
In this study those women who had married at age less 18 years were about 2 times more likely to practice suboptimal birth spacing as compared to those who had married at age 18 years or above. This finding is in line with study conducted in Sudan and Jimma Zone $(8,22)$.The reason might be due to those married early could be influenced by family in deciding to have access for health care services like contraceptives.

Educational status of respondents is another significantly associated factor for suboptimal birth spacing practice. In this study, the odds of having suboptimal birth spacing practice were about 2 times more among mothers who had no formal education as compared to their women counterparts who attended formal education. This finding is consistent with evidences from studies conducted in Iran (25), Jimma zone (8), Dodota district (11) , Hadiya zone (9), Illubabor Zone (23), Arbaminch district(16) and Jimma Zone (26).Similarly, study respondents whose husbands had no formal education practice suboptimal birth spacing about 2.6 times as compared to those whose husbands attended formal education. This finding is in line with studies conducted in Sudan (22) and Dabat district (27). This might be explained by the fact that educated women and their husbands are well informed about optimal health care choices and have greater autonomy to make decisions and use quality health care services.

In this study women's who had female index child were about 1.5 times more likely to have short birth interval as compared to mothers who had male index child. Similar findings were obtained from study done in Debremarkos (19), Jimma zone (8), Arba-minch Zuria district (16) and pastoral communities of southern Ethiopia (28). This might be attributed to the reason that a male is considered as a potential economic asset to the family and old age assurance as a whole and it is therefore less likely for mothers to exercise long time breastfeeding or utilize modern contraceptive method as a means of birth control until they get the desired number of sons.

Our finding demonstrated that HEWs are one of the factor which significantly affects birth spacing practice of women's. women who didn't took optimal birth interval education from HEWs increased the likelihood of suboptimal birth spacing practice by two times. Even though there is no study that assess the contribution of HEWs on the practice of suboptimal birth spacing, HEWs are an effective facilitators of interventions for family planning. Moreover the HEWs are the main and trustworthy source of information about familly planning and optimal birth sapcing practice.

In this study, overall breastfeeding duration is found to be the strongest predictor of birth interval duration. Breastfeeding duration is directly related to duration of birth interval i.e., women who breastfed their index child for less than 24 months were about 5 times more likely to give birth within-short birth interval duration as compared with those who breast feed for more than 24 months and above. This is in line with studies conducted in Pakistan (30), Nigeria (31), Dodota district (11), Dabat (27), Arbaminch district (16). This could be due to the effect of breastfeeding which results in lactational amenorrhea, extends postpartum infertility by suppressing ovulation and reducing the chance of conception through hormonal effect. 
Contraceptive utilization status was another variable associated with suboptimal birth spacing practice in this study. Women who didn't use any contraceptive method between index child and last pregnancy were about 6 times more likely to give birth in suboptimal birth interval. This finding is in line with studies in Uganda and Zimbabwe (32) Pakistan (30), Sudan (22), Debremarkos (19), Jimma Zone (8), Dodota district (11), Dabat district (27), and Arbaminch district (16).

Findings from this study revealed that mothers who had poor knowledge about optimal birth spacing practice were about 3 times more likely experience suboptimal birth spacing practice as compared to those who had good knowledge. This finding is similar with study conducted in Myanmar which reveals mothers who had poor knowledge about optimal birth spacing were 3 times more likely practice short birth interval (33). These may be due to the fact that having awareness about advantages and disadvantages of short birth interval for both child and mother makes them to use modern contraceptives as well as breast feed their child until optimum time.

\section{Limitation of the study}

This data was collected through self -report of the respondents where there could be social desire bias and as it was cross-sectional type, it doesn't indicate cause and effect relationship. Besides, though birth interval can be explained by social and cultural issues, the questionnaire did not extend to investigate such issue in depth. Finally, consecutive birth intervals and breastfeeding duration were calculated based on the women recall, which may result in recall and reporting biases.

\section{Conclusion And Recommendation}

Optimum birth spacing have significant role in reducing both maternal and child mortality as well as morbidity .However, more than half of the study respondents were practicing suboptimal birth interval in this study. Difference in socio demography and biological factors could made variation on birth interval between families. Educational status of mothers and husbands, age at first marriage, HEW workers education about birth spacing, duration of breastfeeding less than 24 months, poor knowledge about optimum birth spacing and not using of modern contraceptives were independent predictors of suboptimal birth spacing practice. Majority of women in this study had information for at least one modern contraceptive but they were either misinformed or had no factual information about optimal birth interval duration. Duration of breast feeding is one of mechanism to optimally space births occurred consecutively. Even though all study respondent's breast feed their index child, there is variation on duration they feed and majority stop breast feeding due to occurrence of new pregnancy. Health office higher officials should give attention and work on creating awareness about the importance of spacing child optimally. They should better induce the child bearing age mothers that birth spacing is the most crucial intervention for the health of both mother and the child born to her, even helpful in building ones economic condition of individual to the country level at large.

Furthermore, the Ethiopian Ministry of Health together with its stakeholders is better to strengthen the existing strategies of providing information, education, and communication by giving critical attention to 
women and their husbands to advance their awareness about the importance of modern contraceptive utilization, breast-feeding, and optimal birth spacing.

\section{Abbreviations}

AHR: Adjusted Hazard Ratio, ANC: Antenatal Care, AOR: Adjusted Odds Ratio, Cl: Confidence Interval, EDHS: Ethiopian Demographic Health Survey, FP: Family Planning, FMOH: Federal Ministry of Health, HEP: Helath Extension Program, HEWs: Health Extension Workers, $\mathrm{MCH}$ : Maternal and Child Health, PPA: Postpartum Amenorrhea, IPI: Inter Pregnancy Interval, IUCD: Intra Uterine Contraceptive Device, SNNPR: Southern Nations, Nationalities and Peoples Representative, UN: United Nations, UNICEF: United Nations International Children's Emergency Fund, USAID: United States Agency for International Development, WHO: World Health Organization

\section{Declarations}

\section{Ethical approval and consent to participant}

Ethical clearance was obtained from Institutional Review Board (IRB) of Hawassa University College of Medicine and Health Science and it was submitted to, SNNPR health bureau, hadiya zone health office and West Badwacho district health office in order to get official letter of permission for data collection. Participation information was collected anonymously after obtaining informed written consent from each respondent by assuring confidentiality throughout the data collection period. In order to maintain confidentiality the participants were assured that the obtained information is not made available to anyone who was not directly involved in the study and their names are not written on the questionnaire.

\section{Availability of data and material}

All related data has been presented within the manuscript. The data set supporting the conclusions of this article is available from the authors on request.

\section{Consent for publication}

Not applicable

\section{Funding}

Hawassa University had covered all research costs including data collection, data entry and payments for supervisors and advisors.

\section{Competing interests}

The authors declare that no one has competing interests.

\section{Authors' contribution}


AW and YS was involved in the conception, design, analysis, interpretation, report and manuscript writing; TA and AY were participated in the design, analysis, interpretation and report writing. and all authors have read and approved the final manuscript

\section{Acknowledgment}

The authors thank Hawassa University for approval of ethical clearance, technical and financial support of this study. Then, we would like to thank all study participants who participated in this study for their commitment to responding to our interviews and observations. Lastly, we are indebted to each department's health offices for their assistance and permission to undertake the research.

\section{References}

1. World Health Organization.Report of a WHO technical consultation on birth spacing: Geneva, Switzerland 13-15 June 2005. World Health Organization, 2007.

2. Herndn D, Reynaldo M, Robert K: Nutrition, lactation, and birth interval components in rural Guatemala. Am J Clin Nuir 1982, 35:1468-1476.

3. USA.USAID. United States agency for international development Strengthening family planning policies and programs in developing countries. 2005.

4. Conde-Agudelo A, Rosas-Bermudez A, Castaño F, Norton MH. Effects of birth spacing on maternal, perinatal, infant, and child health: a systematic review of causal mechanisms. Studies in family planning. 2012;43(2):93-114.

5. Rutstein SO. trends in birth spacing. USA: 2011 Contract No.: 28.

6. Haile K, Gebremedhin M, Berhane H, Gebremedhin T, Abraha A, Berhe N, et al. Desire for birth spacing or limiting and non-use of long acting and permanent contraceptive methods among married women of reproductive age in Aksum Town, North Ethiopia. Contraception and reproductive medicine. 2016; 1(1):22.

7. Shiferaw S, Abdullah M, Mekonnen Y, Maïga A, Akinyemi A, Amouzou A, et al. Trends in contraceptive use and distribution of births with demographic risk factors in Ethiopia: a subnational analysis. Global health action. 2015;8(1):29720.

8. Ayane GB, Desta KW, Demissie BW, Assefa NA, Woldemariam EB. Suboptimal child spacing practice and its associated factors among women of child bearing age in Serbo town, JIMMA zone, Southwest Ethiopia. Contraception and reproductive medicine. 2019;4(1):4.

9. Yohannes S, Wondafrash M, Abera M, Girma E. Duration and determinants of birth interval among women of child bearing age in Southern Ethiopia. BMC pregnancy and childbirth. 2011;11(1):38.

10. Gupta PM, Freedman AA, Kramer MR, Goldenberg RL, Willinger M, Stoll BJ, et al. Inter-pregnancy Interval and Risk of Stillbirth: A Population-based Case Control Study. Annals of epidemiology. 2019.

11. Seifadin A. Duration of Birth Interval and Associated Factors among Married Women in Dodota Woreda, Arsi Zone, Ethiopia: Harmaya University; 2016. 
12. Nisha MK, Alam A, Islam MT, Huda T, Raynes-Greenow C. Risk of adverse pregnancy outcomes associated with short and long birth intervals in Bangladesh: evidence from six Bangladesh Demographic and Health Surveys, 1996-2014. BMJ open. 2019;9(2):e024392.

13. Bekele A, Lakew Y. Projecting Ethiopian Demographics from 2012-2050 Using the Spectrum Suite of Models. Ethiopian Public Health Association (EPHA): Addis Ababa, Ethiopia. 2014.

14. Ethiopian demographic health survey .key indicators finding 2016.

15. Dadi AF. A systematic review and meta-analysis of the effect of short birth interval on infant mortality in Ethiopia. PloS one. 2015;10(5):e0126759.

16. Hailu D, Gulte T. Determinants of short interbirth interval among reproductive age mothers in Arba Minch District, Ethiopia. International journal of reproductive medicine. 2016;2016.

17. Ejigu T. Effect of quality antenatal care service on the continuum of maternal and newborn health care services; a follow up study at public health facilities of Bahir-dar city administration; North West Ethiopia: Addis Ababa Universty; 2018.

18. Ethiopian demographic health survey key indicators .2019.

19. Ejigu AG, Yismaw AE, Limenih MA. The effect of sex of last child on short birth interval practice: the case of northern Ethiopian pregnant women. BMC research notes. 2019;12(1):75.

20. Gebrehiwot SW, Abera G, Tesfay K, Tilahun W. Short birth interval and associated factors among women of child bearing age in northern Ethiopia, 2016. BMC women's health. 2019;19(1):85.

21. West Badwacho woreda health department report ,Hadiya zone, South Ethiopia ,2019.

22. Ali AA, Yassin K, Ramadan N. Determinant of Inter-Pregnancy Birth Interval in Kassala, Eastern Sudan. Current Women's Health Reviews. 2014;10(1):5-8.

23. Tsegaye D, Shuremu M, Bidira K. Practice of child spacing and its associated factors among women of child bearing age (15 to 49 years) in Illubabor zone, south West Ethiopia. International Journal of Nursing and Midwifery. 2017;9(7):102-8.

24. Exavery A, Mrema S, Shamte A, Bietsch K, Mosha D, Mbaruku G. Non-adherence of WHO recommended inter-birth interval in Rufiji, Tanzania. BMC Pregnancy Childbirth [serial on internet]. 2012.

25. Mohammadi Farrokhran E, Mahmoodi M, Mohammad K, Rahimi A, Majlesi F, Parsaeian M. Study of factors affecting first birth interval using modified Gompertz cure model in west Azarbaijan province, Iran. Iranian Journal of Epidemiology. 2013;9(1):41-51.

26. Dibaba Y. Child spacing and fertility planning behavior among women in mana district, Jimma Zone, South West Ethiopia. Ethiopian journal of health sciences. 2010;20(2).

27. Tessema GA, Zeleke BM, Ayele TA. Birth interval and its predictors among married women in Dabat District, Northwest Ethiopia: A retrospective follow up study. African journal of reproductive health. 2013;17(2):39-45.

28. Begna Z, Assegid S, Kassahun W, Gerbaba M. Determinants of inter birth interval among married women living in rural pastoral communities of southern Ethiopia: a case control study. BMC 
pregnancy and childbirth. 2013;13(1):116.

29. Fallahzadeh H, Farajpour Z, Emam Z. Duration and determinants of birth interval in Yazd, Iran: a population study. Iranian journal of reproductive medicine. 2013;11(5):379.

30. Kamal A, Pervaiz MK. Determinants of higher order birth intervals in Pakistan. Journal of Statistics. 2012;19(1).

31. Kemi OB, Olurotimi OJ. Breastfeeding and child spacing among women in South West Nigeria. International Journal for Cross-Disciplinary Subjects in Education (IJCDSE). 2011;2(2):414-20.16.

32. McGuire C, Stephenson R. Community factors influencing birth spacing among married women in Uganda and Zimbabwe. African journal of reproductive health. 2015;19(1):14-24.

33. Nyein C, Keiwkarnka B, Sillabutra J. Factors affecting the birth spacing among rural pregnant women in Salin Township, myanmar. Journal of Health Research. 2014;28(3):165-71.

\section{Table}

Table 5: Associated factors of suboptimal birth spacing among child bearing age mothers in West Badwacho district ,Hadyia Zone ,South Ethiopia, 2020 , (N=626) 


\begin{tabular}{|c|c|c|c|c|}
\hline \multirow[t]{2}{*}{ Variables $(\mathrm{N}=626)$} & \multicolumn{2}{|c|}{$\begin{array}{l}\text { Suboptimal birth } \\
\text { interval }\end{array}$} & \multirow[t]{2}{*}{$\begin{array}{l}\text { COR }(p<0.25) \\
\text { AOR }\end{array}$} & \multirow[t]{2}{*}{ AOR } \\
\hline & Yes & No & & \\
\hline \multicolumn{5}{|l|}{ Age of the mother } \\
\hline $20-24$ & 66 & 46 & $0.78(0.39-1.55)$ & $\begin{array}{l}0.65(0.12- \\
3.52)\end{array}$ \\
\hline $25-29$ & 120 & 61 & $1.07(0.55-2.05)$ & $\begin{array}{l}1.30(0.33- \\
5.05)\end{array}$ \\
\hline $30-34$ & 90 & 50 & $0.98(0.50-1.91)$ & $\begin{array}{l}1.04(0.33- \\
3.27)\end{array}$ \\
\hline $35-39$ & 69 & 73 & $0.51(0.26-0.99)$ & $\begin{array}{l}0.51(0.22- \\
1.16)\end{array}$ \\
\hline$\geq 40$ & 33 & 18 & 1 & 1 \\
\hline \multicolumn{5}{|l|}{ Age at first marriage } \\
\hline$<18$ years & 43 & 107 & $1.25(0.90-1.720)$ & $\begin{array}{l}2.18(1.34- \\
3.53)\end{array}$ \\
\hline$\geq 18$ years & 235 & 141 & 1 & 1 \\
\hline \multicolumn{5}{|l|}{ Residence } \\
\hline Urban & 77 & 79 & $0.55(0.37-0.78)$ & $\begin{array}{l}1.15(0.66- \\
1.98)\end{array}$ \\
\hline Rural & 169 & 301 & 1 & 1 \\
\hline \multicolumn{5}{|c|}{ HEWs birth spacing education } \\
\hline Yes & 158 & 132 & 1 & 1 \\
\hline No & 220 & 116 & $1.58(1.14-2.18)$ & $\begin{array}{l}1.89(1.02- \\
3.48)\end{array}$ \\
\hline \multicolumn{5}{|l|}{ Maternal education } \\
\hline $\begin{array}{l}\text { Non formal } \\
\text { Education }\end{array}$ & 299 & 157 & $2.19(1.53-3.13)$ & $\begin{array}{l}2.25(1.31- \\
3.87)\end{array}$ \\
\hline Formal education & 79 & 91 & 1 & 1 \\
\hline \multicolumn{5}{|l|}{ Maternal } \\
\hline \multicolumn{5}{|l|}{ Occupation } \\
\hline House wife & 217 & 140 & $1.09(0.67-1.76)$ & $1.20(0.45-$ \\
\hline
\end{tabular}




\begin{tabular}{|c|c|c|c|c|}
\hline Farmer & 98 & 54 & $1.28(0.75-2.20)$ & $\begin{array}{l}1.11(0.40- \\
3.07)\end{array}$ \\
\hline Business employee & 51 & 36 & $0.47(0.20-1.09)$ & $\begin{array}{l}1.06(0.36- \\
3.08)\end{array}$ \\
\hline Government & 12 & 18 & 1 & 1 \\
\hline \multicolumn{5}{|l|}{ Employee } \\
\hline \multicolumn{5}{|l|}{ Husband } \\
\hline \multicolumn{5}{|l|}{ Education } \\
\hline Non formal & 278 & 104 & $3.99(2.82-5.64)$ & $\begin{array}{l}2.64(1.74- \\
4.01)\end{array}$ \\
\hline \multicolumn{5}{|l|}{ Education } \\
\hline Formal & 93 & 139 & 1 & 1 \\
\hline \multicolumn{5}{|l|}{ Education } \\
\hline \multicolumn{5}{|c|}{$\begin{array}{l}\text { Knowledge of mothers for birth } \\
\text { spacing }\end{array}$} \\
\hline Poor & 88 & 23 & $2.96(1.81-4.85)$ & $2.96(1.64,5.37)$ \\
\hline Good & 290 & 225 & 1 & 1 \\
\hline
\end{tabular}

Number of live

Birth

\begin{tabular}{|c|c|c|c|c|}
\hline$\leq 2$ & 91 & 63 & $1.22(0.80-1.84)$ & $\begin{array}{l}0.58(0.16- \\
2.18)\end{array}$ \\
\hline $3-4)$ & 164 & 81 & $1.71(1.18-2.48))$ & $\begin{array}{l}0.67(0.24- \\
1.83)\end{array}$ \\
\hline$\geq 5$ & 123 & 104 & 1 & 1 \\
\hline \multicolumn{5}{|c|}{ Sex of index child } \\
\hline Male & 131 & 124 & 1 & 1 \\
\hline Female & 247 & 124 & $1.88(1.36-2.61)$ & $\begin{array}{l}1.58(1.06- \\
2.38)\end{array}$ \\
\hline
\end{tabular}

Breast feeding

Duration

$\begin{array}{lllll}<24 \text { months } & 358 & 207 & 3.54(2.02-6.21) & \begin{array}{l}\text { 4.64(2.32- } \\ 9.29)\end{array}\end{array}$

$\geq 24$ months 20 41 1 1 
Contraceptive use for last child

$\begin{array}{lllll}\text { Yes } & 134 & 187 & 1 & 1 \\ \text { No } & 244 & 61 & 5.58(3.90-7.98) & \begin{array}{l}\mathbf{6 . 3 1}(\mathbf{3 . 9 9}- \\ \text { 9.96) }\end{array}\end{array}$

AOR with bold indicate variables with $P$ value $<0.05$.

\section{Figures}

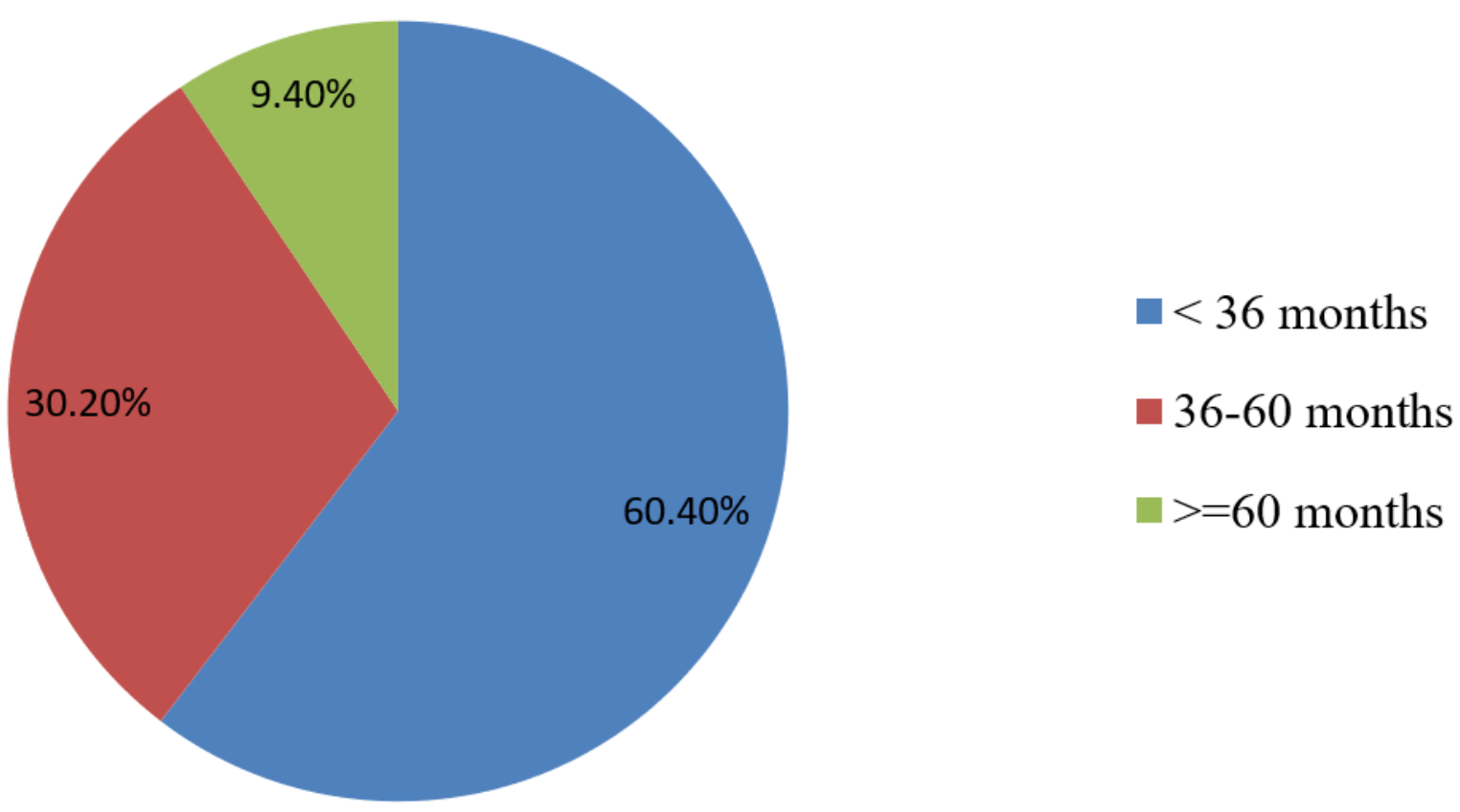

\section{Figure 1}

Distribution of birth intervals among women of reproductive age in West Badwacho district, Hadyia Zone, South Ethiopia, $2020(\mathrm{~N}=626)$ 


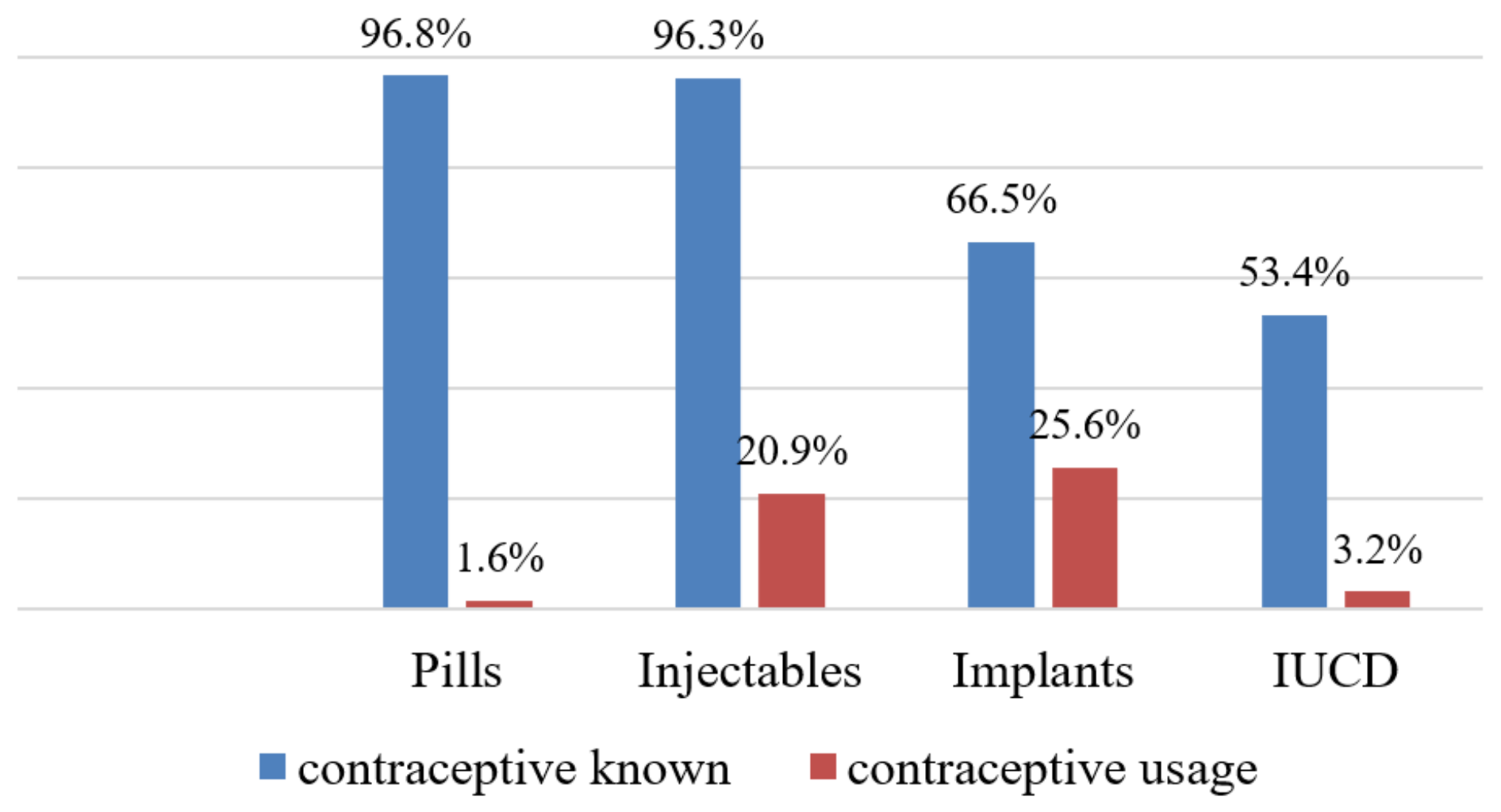

Figure 2

Contraceptive known and usage among mothers of child bearing age in West Badwacho district, Hadyia Zone, South Ethiopia, 2020, $(\mathrm{N}=626)$

\section{Supplementary Files}

This is a list of supplementary files associated with this preprint. Click to download.

- Additionalfile1Englishversionofthequestionery.docx

- Additionalfile2Hadiyaversionofthequestionery.docx

- STROBEcrosssectionalchecklist1.docx 